\title{
Review of free data processing software for chromatography
}

\author{
Lukasz Dąbrowski \\ UTP University of Science and Technology, Institute of Food Analysis and Environmental Protection, \\ Faculty of Technology and Chemical Engineering, ul. Seminaryjna 3, 85-326 Bydgoszcz, POLAND
}

\begin{abstract}
An overview of several useful free of charge (FoC) and freely available computer software programs for chromatograms post-processing were presented. Their possible field of the use and basic features were discussed. The following computer software were described: Wsearch32, OpenChrom, ezData, Unichrom, AMDIS. Many advanced functions available in these computer programs make them appropriate for everyday use in chromatographic labs.
\end{abstract}

Keywords: Free of charge software, Chromatography, Chromatogram post-processing, Chromatography software, Chromatography data system

\section{Introduction}

Nowadays chromatographic systems are usually connected directly to personal computers PCs either to control chromatography and acquire chromatographic data (DAQ) or to analyze the obtained results. These fundamental tasks are implemented into two independent computer programs (on-line and off-line versions) or embedded in one software or at least one interface. Computer programs (known also as chromatography data systems) used today have many additional functions of annotation, calibrating, reporting, batch processing to name a few of them.

The computer software is mostly a part of the whole chromatograph-PC system sold by a manufacturer. Usually it is protected by special methods (software or USB key) to be installed accordingly to the number of licenses bought by the user. Additional software licenses are sometimes cheaper as compared to the one pre-installed on the computer used to control chromatograph. The chromatographic data are also usually reprocessed in a location different from the noisy chromatographic lab. In this case, the use of another different from the original pre-installed software may also reduce costs.

Free of charge (FoC) computer software programs are a good alternative for this task. This kind of software usually has many import/export chromatographic data filters which makes them useful in data post-processing of proprietary data files.

Free of charge computer software can also be an additional advantage for the general purpose $\mathrm{A} / \mathrm{D}$ converter when connected to the output of an analog signal from the detector. Dedicated acquisition computer software which comes with the converter does not have specific functions used in chromatography. In many situations, such as computer failure, non typical experiments, testing, training, such chromatography data acquisition (DAQ) system (nowadays at the price even below 50 USD) could be a solution.

From the educational aspect, a unified postprocessing program with the ability of opening many vendors' specific data files allows the chemist's focus to lie on subsequent chromatographic tasks rather than computer program operation. Many $\mathrm{FoC}$ software programs can be considered universal solution for all chromatographic data originated from various vendors. Furthermore, because they are freely available on internet, they are easily accessible to both students and staff. An overview of the possible usage of some FoC computer programs is shown in Figure 1 bellow.

The aim of this work is to provide information on free-of-charge software for chromatography which can be used in all or some of the purposes described above. These computer programs are available on internet and some of them are not widely known in chromatographic society.

Free of charge computer software for chromatography - overview

There were several criteria for choosing the software for this review. Computer software presented in this article are free of charge for educational and commercial purposes (formally available under different licenses: like open source, freeware, and commercial etc. Alpha-stage, without installer (i.e. programs to be compiled by user) or manufacturer, specific software (free software but dedicated to specific hardware only) as well as the software requiring complicated installation of various additional libraries, were not described. 
The programs reviewed in this work have the capability of opening chromatographic data from vendor-specific data formats or universal text format thanks to their functional universality. The computer software programs chosen for this study are presented in Table 1.

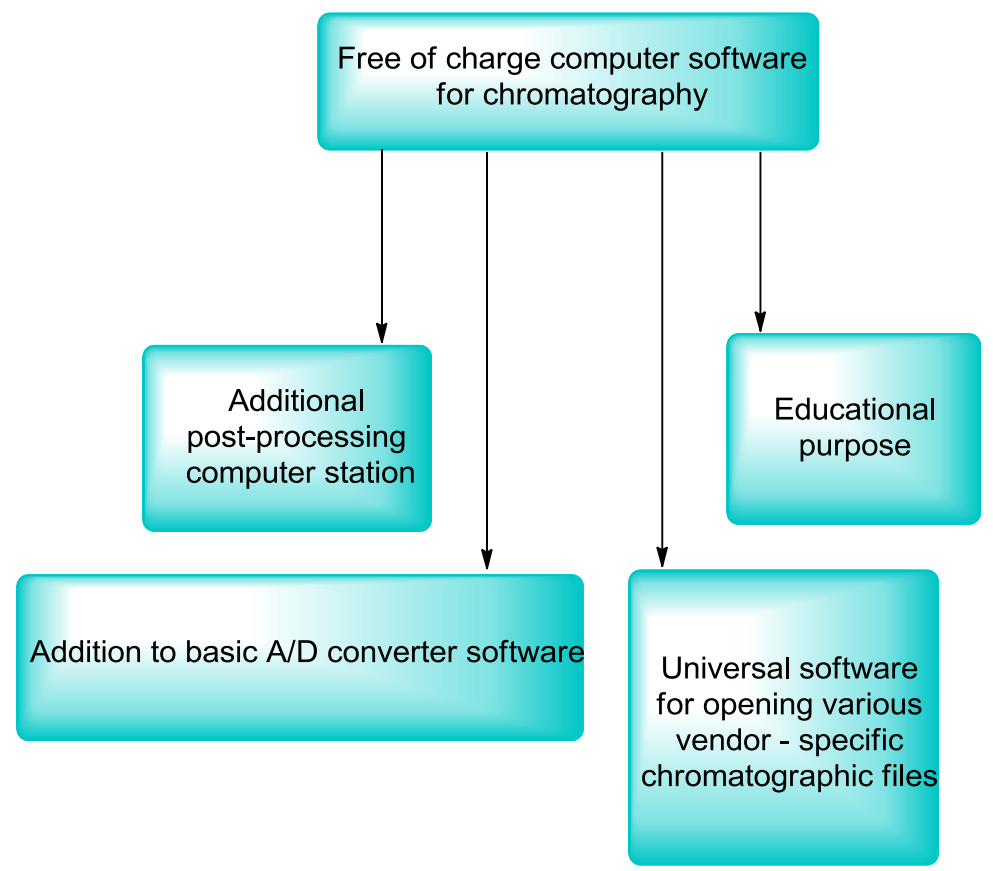

Figure 1. Overview of the usage of free of charge (FoC) computer software

Table 1. Basic information on GC free of charge software*

\begin{tabular}{|c|c|c|c|c|}
\hline $\begin{array}{l}\text { Computer } \\
\text { software }\end{array}$ & $\begin{array}{l}\text { software status / } \\
\text { version (date) }\end{array}$ & Documentation & website & System requirements \\
\hline ezData & $\begin{array}{l}\text { freeware, } \\
\text { opensource; } \\
(2004)\end{array}$ & $\begin{array}{l}\text { manual form } \\
\text { website }\end{array}$ & http://dabrowski.utp.edu.pl/chrom & $\begin{array}{l}\text { Windows } \\
\text { later, } 95, \mathrm{NT} \text { and } \\
\text { linux (wine) }\end{array}$ \\
\hline UniChrom $^{\mathrm{TM}}$ & $\begin{array}{l}\text { commercial but } \\
\text { data processing is } \\
\text { free, version } 5 . \mathrm{x} \\
(2015)\end{array}$ & $\begin{array}{l}\text { manual form } \\
\text { website, program } \\
\text { help }\end{array}$ & http://www.unichrom.com/ & $\begin{array}{l}\text { Windows } \\
\text { next, Linux } 95, \text { NT and } \\
\text { (wine), Linux }\end{array}$ \\
\hline Wsearch32 & $\begin{array}{l}\text { freeware - version } \\
1.6 .2005(2005)\end{array}$ & program help & $\begin{array}{l}\text { http://www.wsearch.com.au/wsearc } \\
\text { h32/wsearch32.htm }\end{array}$ & $\begin{array}{l}\text { Windows } \\
\text { Linux (wine) }\end{array}$ \\
\hline OpenChrom & $\begin{array}{l}\text { open source, free } \\
\text { community edition } \\
\text { data import filters } \\
\text { - free; version } 1.0 \\
(2015)\end{array}$ & $\begin{array}{l}\text { available on } \\
\text { website, video } \\
\text { tutorials, program } \\
\text { help - under } \\
\text { development }\end{array}$ & http://www.openchrom.net & $\begin{array}{l}\text { Java } 7^{\mathrm{TM}}, \text { Windows } \\
\text { Linux, Mac OSX } \\
\text { Solaris } \\
\text { TM }^{\mathrm{TM}}\end{array}$ \\
\hline AMDIS $^{\text {TM }}$ & $\begin{array}{l}\text { freeware, version } \\
2.71(2012)\end{array}$ & $\begin{array}{l}\text { manual (pdf), } \\
\text { program help }\end{array}$ & $\begin{array}{l}\text { http://chemdata.nist.gov/dokuwiki/d } \\
\text { oku.php?id=chemdata:amdis }\end{array}$ & $\begin{array}{l}\text { Windows } \\
\text { later, Linux } 2000 \text { and } \\
\text { laine) }\end{array}$ \\
\hline
\end{tabular}

\footnotetext{
*All trademarks are property of respective owners.

Post-processing capabilities of computer software for chromatography

Among many various features which can be used to describe chromatographic computer software we may find the number of the data formats which can be maintained by the program, the way chromatographic data can be displayed on the screen, the number of functions to process chromatograms and the possibility of calibration and report generation.
}

\section{Data formats}

Almost every manufacturer has its own data format which is not always compatible with the others. The bundled programs usually do not offer access to other than native files. There is sometimes the possibility to export or import AIA-CDF (Chromatograph Data File in the standard format specified by the Analytical Instrument AssociationAIA) or ASCII text files in different internal syntax. Except AIA CDF, ASCII text files (in csv or another 
format) and sometimes Excel files there is no universal data exchange format. Although the latter format can be used to construct charts, it is often too small to maintain chromatographic data. A dedicated software is necessary to perform such tasks as integration, peak identification etc. Such utility together with many vendor - specific format reading features are offered by FoC computer programs like Wsearch32, UniChrom ${ }^{\mathrm{TM}}$ or OpenChrom ${ }^{\mathrm{TM}}$. There are also some free computer software programs which can read chromatographic ASCII text files (Table 2).

Table 2. Data formats supported in the tested software

\begin{tabular}{|c|c|c|c|}
\hline Computer software & import formats & export data formats & export graph formats \\
\hline ezData & $\begin{array}{l}\text { text files, binary files to be } \\
\text { defined by user }\end{array}$ & $\begin{array}{l}\text { text files (csv, tab) } \\
\text { native "ezd" files, clipboard }\end{array}$ & vector, bitmap formats, clipboard \\
\hline UniChrom $^{\mathrm{TM}}$ & $\begin{array}{l}\text { text files, a lot of pre-defined } \\
\text { vendor-specific data formats }\end{array}$ & $\begin{array}{l}\text { AIA CDF, ASCII, native files, } \\
\text { binary files }\end{array}$ & $\begin{array}{l}\text { clipboard (WMF, EMF); data } \\
\text { from report can be saved as EMF }\end{array}$ \\
\hline WSearch32 & $\begin{array}{l}\text { over } 20 \mathrm{GC} / \mathrm{MS} \text { and MS } \\
\text { vendor-specific data formats }\end{array}$ & $\begin{array}{l}\text { clipboard, "save as" not } \\
\text { available in freeware version, }\end{array}$ & clipboard (WMF, bitmap) \\
\hline OpenChrom & $\begin{array}{l}\text { AIA CDF, ASCII, vendor- } \\
\text { specific MS and other data } \\
\text { formats }\end{array}$ & $\begin{array}{l}\text { ASCII, MS-formats } \\
\text { OpenChrom format (ocb); } \\
\text { clipboard }\end{array}$ & $\begin{array}{l}\text { many build-in filters, more can be } \\
\text { installed as plug-ins }\end{array}$ \\
\hline AMDIS $^{\text {TM }}$ & $\begin{array}{l}\text { AIA CDF, vendor-specific } \\
\text { GC/MS data formats }\end{array}$ & mass spectrum (msp) & TIC as txt file \\
\hline
\end{tabular}

WMF - windows metafile; EMP - enhanced metafile; TIC - Total Ion Current

\section{Data display}

Any post-processing chromatography software should have some basic functions like displaying chromatograms with additional data (filename, date etc.), zooming in and out, changing colors, fonts, axis, labels adding annotations etc. These view options are usually available through main menu and allow to choose the information displayed together with the chromatogram curve. One of the important features is the possibility of chromatogram overlay that allows quick evaluation of similarity for two or more chromatograms. All of the reviewed software have their own options for adjusting the way of chromatogram to be displayed, according to users needs.

\section{Chromatogram processing}

There are many functions available in chromatography post-processing programs but their names for the analogous tasks are sometimes different. For example, the task "integration" can consist of baseline determination, peak searching, integration and substance identification (called also peak matching). In some chromatographic software these functions are separated and subsequent tasks should be performed by user to get common integration results as retention time, beginning and end of the peak, peak height and area etc. In other software "integration" is a function which encompasses all of the mentioned tasks.

There is usually the possibility of data filtering as a preparation for the integration task - performed mainly for noisy signals. For the selected FoC computer programs, the availability of these functions is presented in Table 3 .

Table 3. Basic functions available in described computer software

\begin{tabular}{|c|c|c|c|c|c|c|c|c|}
\hline $\begin{array}{c}\text { Computer } \\
\text { software }\end{array}$ & $\begin{array}{c}\text { data } \\
\text { filtering }\end{array}$ & $\begin{array}{c}\text { baseline } \\
\text { determination }\end{array}$ & integration & $\begin{array}{c}\text { peak } \\
\text { matching } \\
\text { /finding }\end{array}$ & $\begin{array}{c}\text { MS library } \\
\text { search }\end{array}$ & $\begin{array}{c}\text { manual } \\
\text { integration }\end{array}$ & calibration & reporting \\
\hline ezData & yes & \multicolumn{2}{|c|}{ in one process } & yes & no & yes & no & no \\
\hline UniChrom & yes & \multicolumn{2}{|c|}{ in one process } & yes & no & yes & yes & yes \\
\hline WSearch32 & no & \multicolumn{2}{|c|}{ in one process } & no & yes & yes & no & no \\
\hline $\begin{array}{c}\text { OpenChrom } \\
\text { TM }\end{array}$ & yes & yes & yes & yes & yes & yes & yes \\
\hline AMDISTM & no & \multicolumn{2}{|c|}{ in one process } & no & yes & no & no & yes \\
\hline
\end{tabular}




\section{Calibration}

To perform quantitative analysis, a chromatographic system should be calibrated usually with a calibration curve. This option is available only in more advanced FoC computer software i.e. UniChrom ${ }^{\mathrm{TM}}$ or OpenChrom ${ }^{\mathrm{TM}}$.

\section{Report generation}

Reprocessed chromatographic data can be presented in a defined template - called a report. There are several different approaches for the reports. The simplest is that data are just displayed in a predefined form which allows to copy and paste into text editor or spreadsheet (through clipboard). More advanced programs have tools for defining format of the report. Reports can be generated directly in the chromatographic software or externally in a spreadsheet. All of the presented computer programs have at least one such capability.

\section{Chromatographic software overview}

Wsearch32 is very useful computer program in analyzing GC/MS chromatograms (Figure 2). Chromatographic files in many different formats (over 20) as well as spectra - in JCAMP-DX format can be opened and displayed. Some basic functions connected with the peak integration (automatic and manual) are available. It is very easy to connect this program to MS spectral library (NIST) and perform spectra searching using build in Wsearch32 search engine or external one. Chromatograms can be displayed as total ion current plot or/and as extracted (up to 8) ion plots. It is also possible to display several chromatograms in overlay mode. This program can be executed even in older systems and once installed can be moved to other places without need of re-installation. Several articles where Wsearch32 was used to peak integration or spectra processing have been published recently ${ }^{1-3}$.

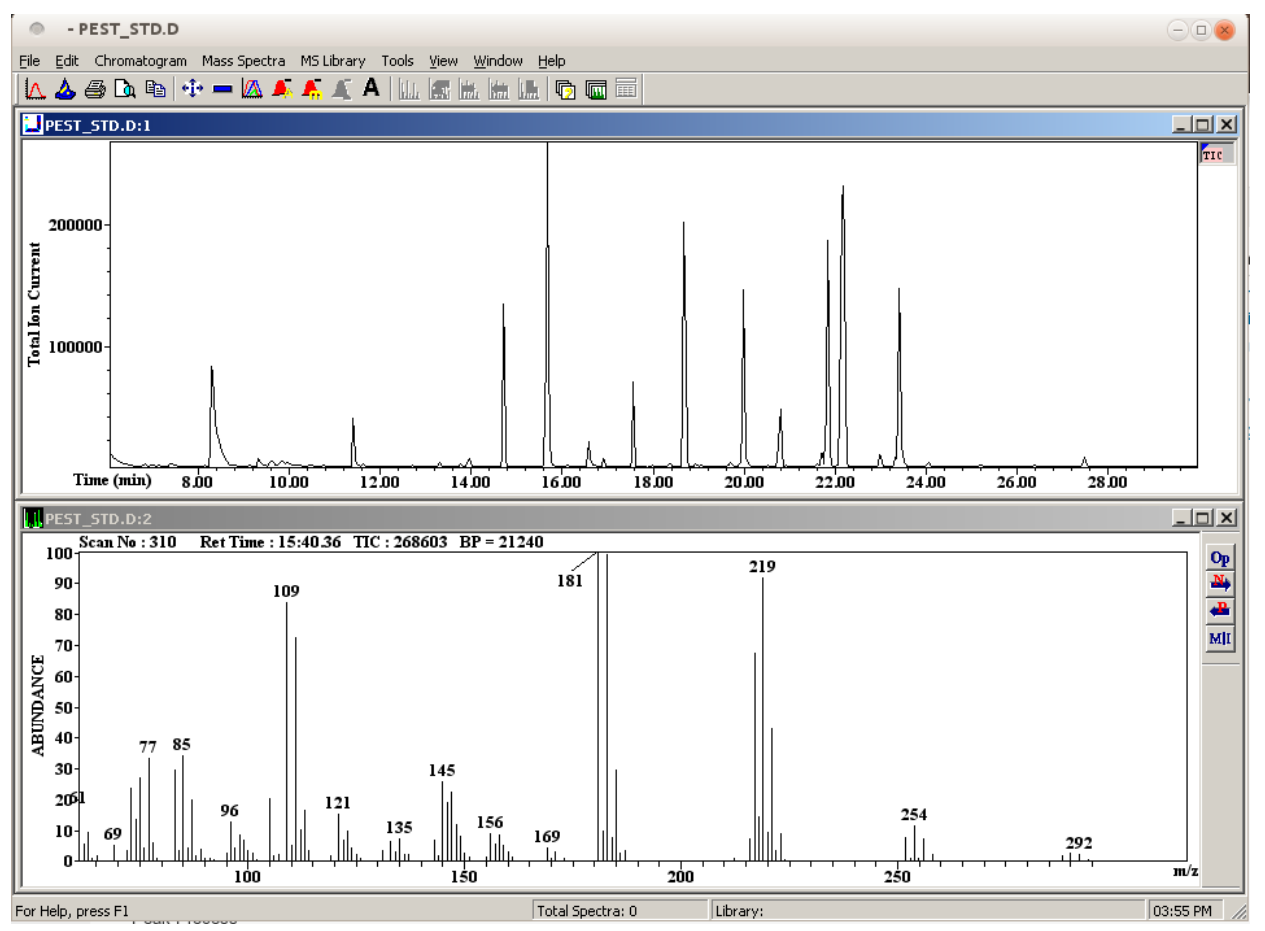

Figure 2. Screenshot of WSearch32 computer software

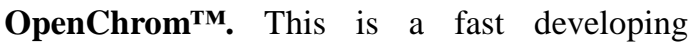
software program for mass spectrometry coupled with chromatography and another techniques. It can also be used to open chromatographic data form onedimensional GC detectors like FID. OpenChrom has many plugins such as import and export file converters that can be downloaded directly from the main menu. This program has all tools needed for the chromatographic data recalculation: data filters, baseline detectors, peak detectors, integrators and peak identifier which can be coupled with the mass spectra library (NIST). It is also possible to make quantitative calculations and generate text report. For the batch processing of the data there is a special, very flexible tool: Batch Process Editor. However there is a very specific style of operation of this computer program i.e. subsequent tasks are available by selecting the proper perspective, such as: Chromatogram overlay, Manual Peak Detector or other (Figure 3). For the user who spends some time getting acquainted with this kind of operation, it would be easy to discover how powerful it is. OpenChrom is really "open" for additions, scripts (Groovy Script). There are several articles published showing the possible use of this software i.e. identification of chromatogram peaks ${ }^{4}$, verification of modeled spectra ${ }^{5}$ and signal smoothing using OpenChrom filters ${ }^{6}$. It is necessary to install Java ${ }^{\mathrm{TM}}$ (can be downloaded for free) to run OpenChrom. Because of $\mathrm{Java}^{\mathrm{TM}}$ - this software has higher computer system requirements than the others reviewed 


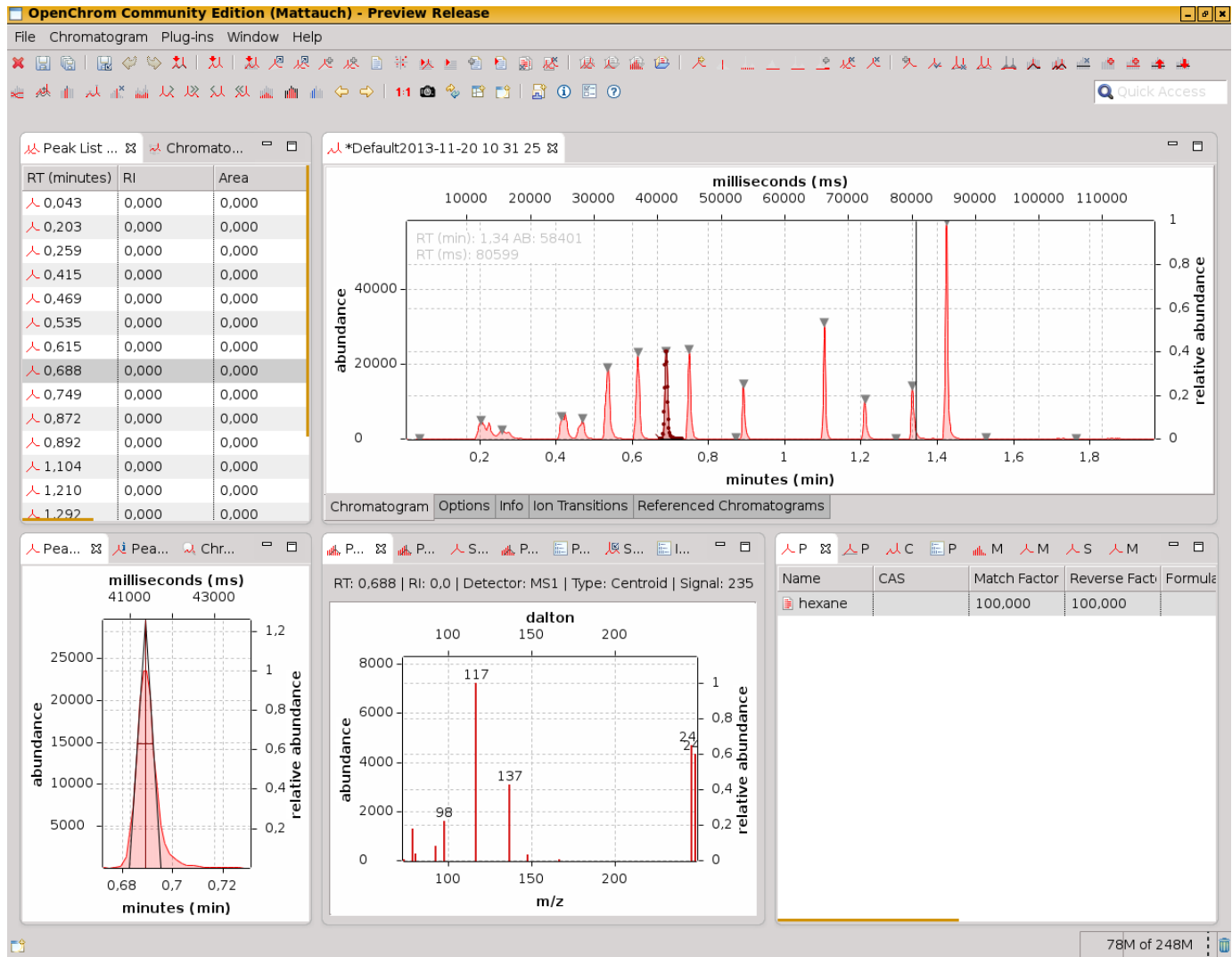

Figure 3. Screenshot of OpenChrom computer software

ezData is a small computer program with great capabilities. With ezData, it is possible to import binary or ASCII text files through "Data Format Manager". To import binary data files, the user have to know their accurate structure which is not always simple. In case of text files, the user has to find and define the file structure. ezData has a tool
"Analyser" to preview the file. This is an universal and effective way of importing many different file formats previously exported from chromatographic software or from data acquisition programs. ezData has several basic functions of viewing, smoothing and integrating chromatograms (Figure 4).

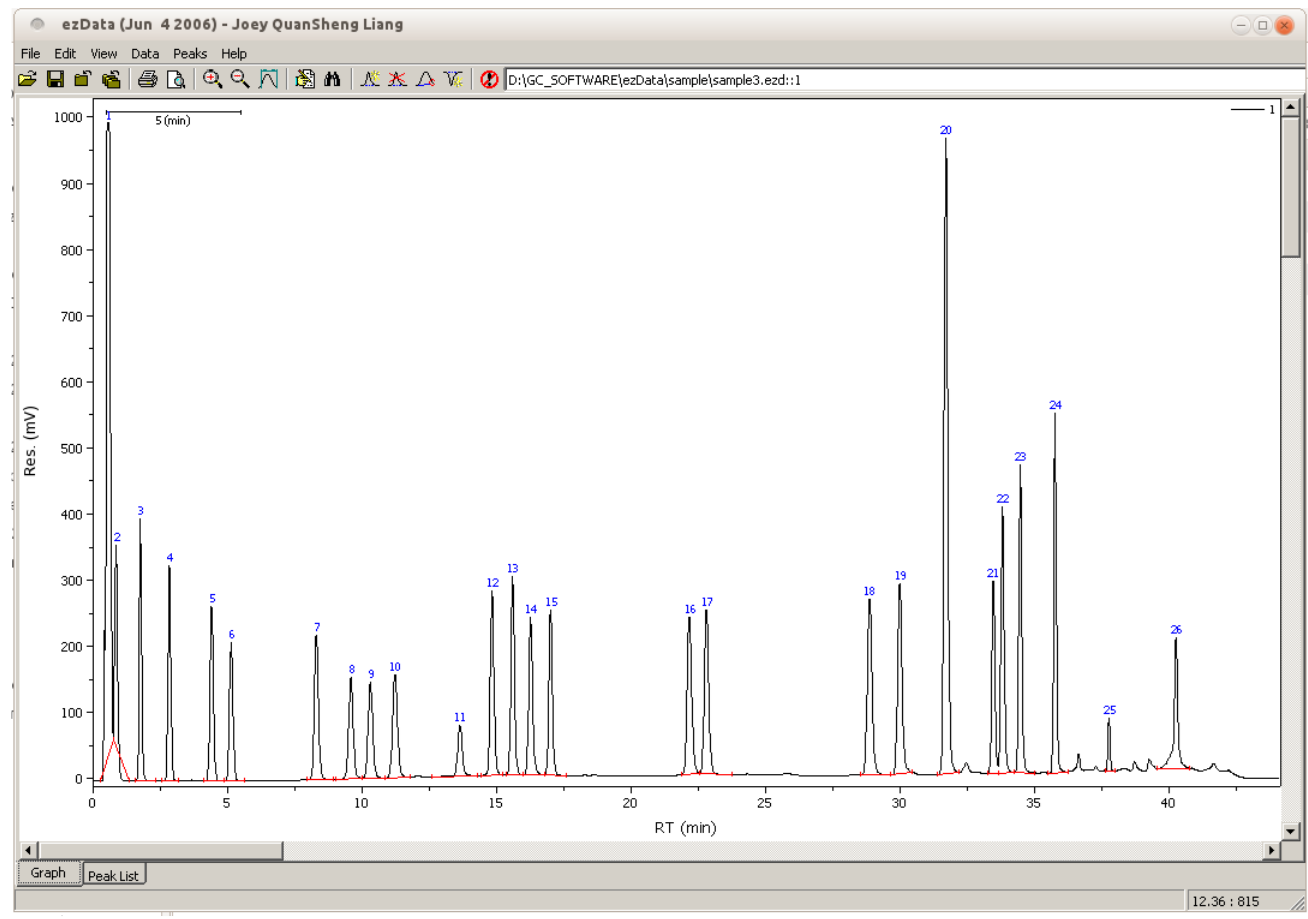

Figure 4. Screenshot of ezData computer software 
Manual integration is easy to operate in this program. Furthermore, it is also possible to correct the baseline of chromatogram by cutting, cropping, merging and overlaying two or more chromatograms. There is also a simple but effective identification function which is peak searching. Report generation and other advanced functions are not available. ezData has almost all what chromatographers need for the system connected to one dimensional detectors like FID, ECD, UV-Vis etc. This program has also a great advantage: there is no need to install it - just unzip and run from any location. Unfortunately, this software is now abandoned, although the source files are available at sourceforge.net ${ }^{7}$. Complied computer program with additional materials are no longer (since 2015) available on author's website (Table 1) but hosted at: http://dabrowski.utp.edu.pl/chrom.

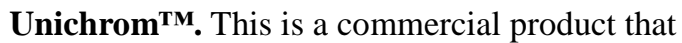
can be downloaded as demo version with full off-line working capabilities. There are generally no restrictions on the software usage. According to the software creator: "Data processing is free i.e. when you not measuring data - do what you want (either educational or commercial purposes) within license terms" ${ }^{8}$. This program can read many different chromatographic formats - either from GC or HPLC instruments. It is possible to import ASCII data. UniChrom, like many commercial chromatographic programs, has an intuitive way of zooming in and out the displayed data like chromatograms or spectrums. Very useful interpretation of integrated peaks is filling the peak contours with color (Figure 5). It is also possible to display chromatograms in many different modes - also in overlay mode. This computer program has very sophisticated functions for the chromatogram reprocessing. There is a possibility to adjust parameters connected with peak finding, integration etc. The sequence of many tasks can be recorded as macro for the future use. Peak identification can be performed basing on the retention time and/or Kovacs indices.

It is also possible to display MS and UV spectra from chromatograms. However, there is an inconsistence in this program which the user should know: the term "spectrum" is used sometimes as a synonym of chromatogram and sometimes as a real spectrum. UniChrom allows to perform tasks as: calibration, quantitative analysis, internal and external (MS Word, MS Excel) reporting.

There are two versions of Unichrom: one for Windows (which also works under wine) and another for Linux (both available in several languages). Several articles were published on UniChrom in Russian, and some in English describing the software features ${ }^{9}$ and its application for the data acquisition and post-processing ${ }^{10}$.

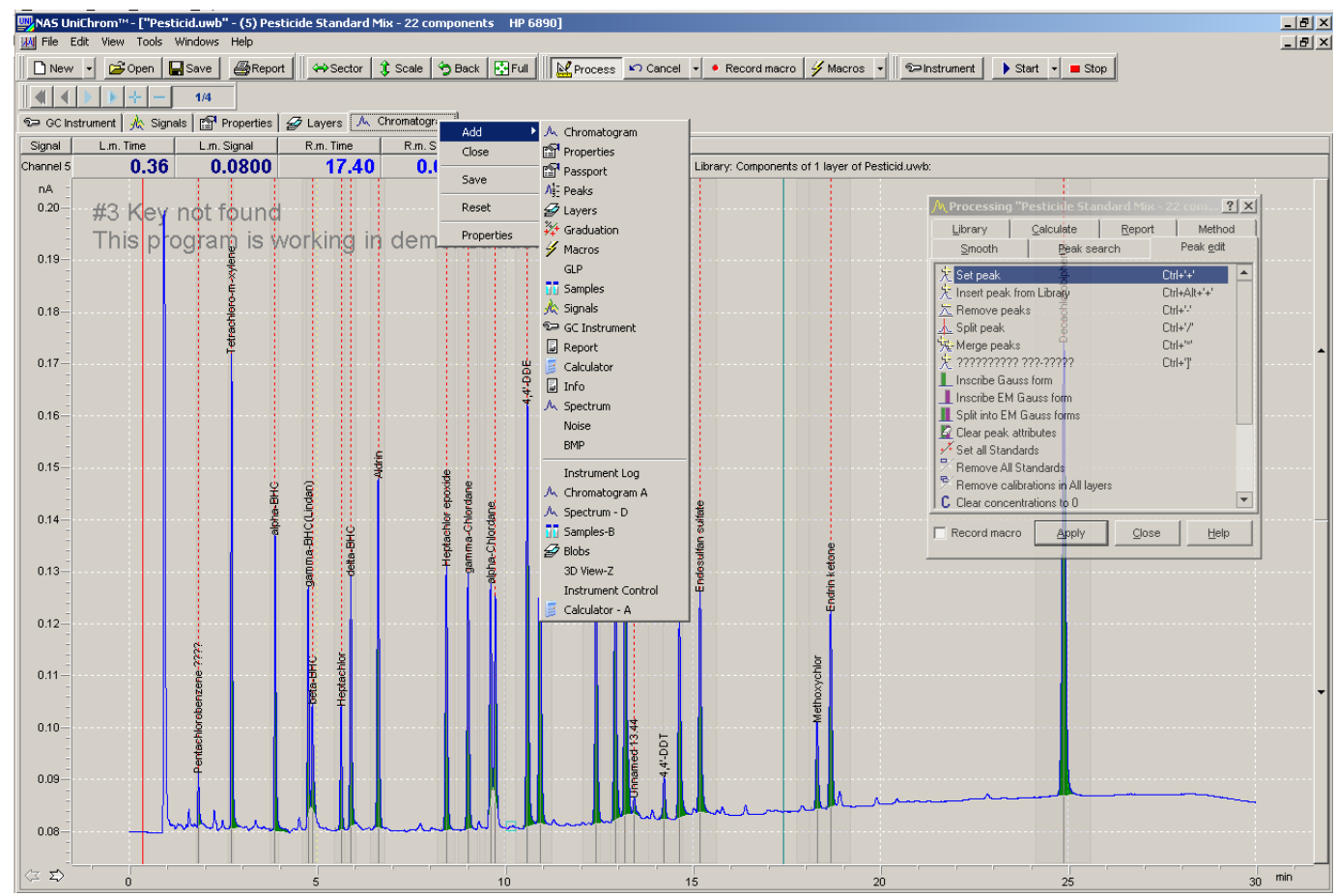

Figure 5. Screenshot of the Unichrom computer software

AMDIS (Automated Mass Deconvolution and Identification System) ${ }^{\mathrm{TM}}$ extracts spectra for individual components in a GC/MS data file and identifies target compounds by matching these spectra against a reference
Library ${ }^{11}$. This is a well-known computer program for all who work with GC/MS data. The program is dedicated mainly to qualitative analysis. It can open and view many GC/MS data formats (Figure 6). 


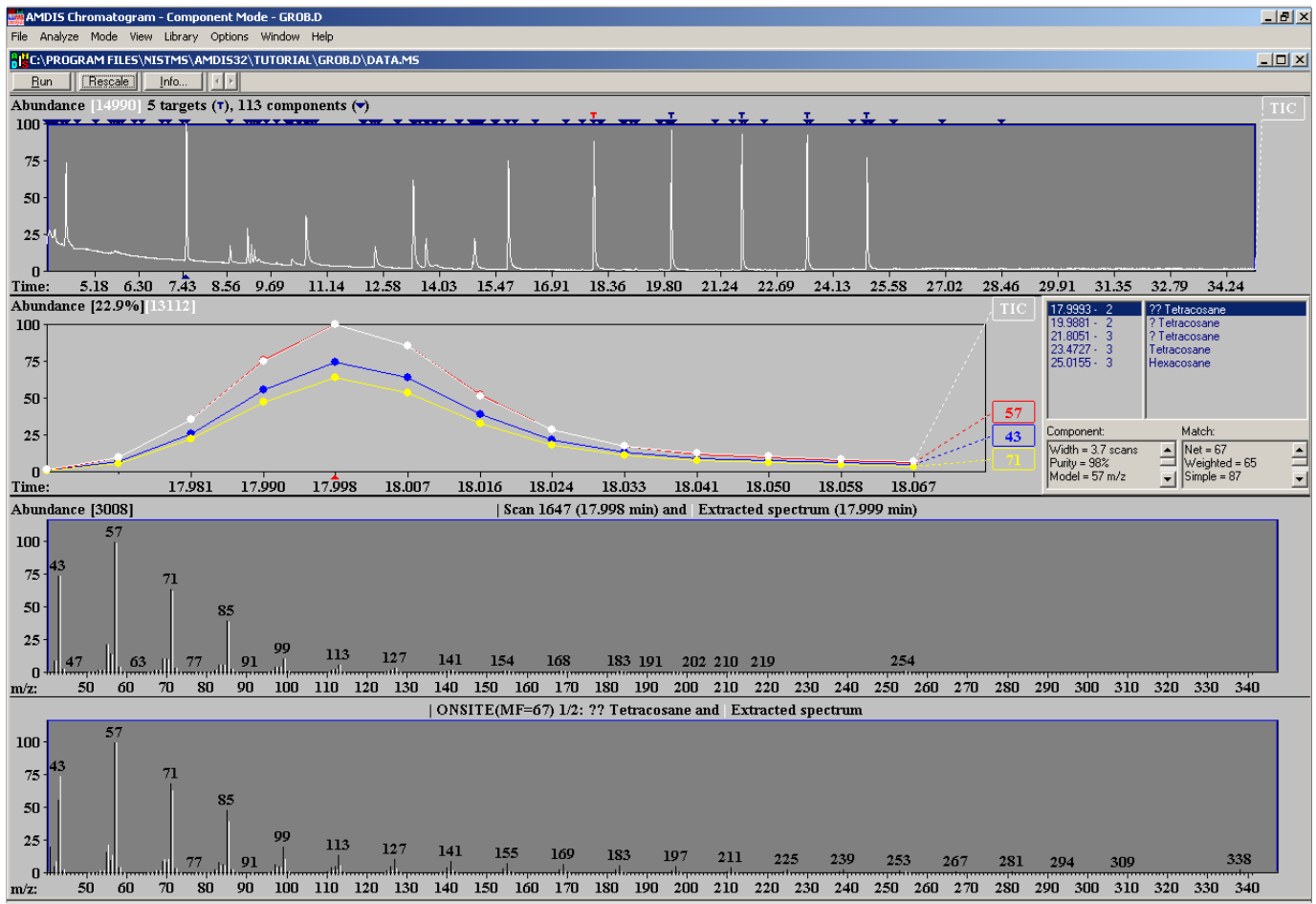

Figure 6. Screenshot of the AMDIS computer software

\section{Z}

AMDIS is designed to work with another NIST product: the mass spectra library. However some functions are available even without the library: viewing, printing, extraction ions form spectra, noise evaluation and the most important is the chemical classification of peaks.

This software has been used for years and many articles have been published on AMDIS applications for automatic identification and quantification of the analytes ${ }^{12-17}$.

\section{Conclusion}

Free of charge (FoC) software for postprocessing of chromatographic data can find their own field of use in almost every GC or HPLC lab. Compared to commercial software, the user is usually required to customize FoC programs for use in a particular data processing purpose.

Commercial software except the advanced functions, similarly to FoC programs, has also builtin wizards which guide the user through the subsequent tasks. In this way the whole process of the chromatogram processing can be accelerated. For routine chromatographic analysis it is really helpful. But in chromatography analysis quite frequently occurs non typical situations. In chromatography analysis, pre-defined post-processing wizard can fail and manual operations are required. For this purpose, free of charge chromatography computer software can be a good alternative or addition to commercial products. For the same reason these programs are also an excellent aid in the stage of education process. Some of FoC programs have unique functions and style of operation and compared to proprietary software, may even perform some tasks

easier. Crucially for the user, they are available for free on Internet and can be used for any purpose with almost no restrictions. Like all computer program those presented in this article may also have some bugs and therefore should be used after individual evaluation.

\section{References}

1- J- Honzíček, A. Mukhopadhyay, C. Bonifacio, C. C. Romão, J. Organomet. Chem., 2010, 695(5), 680686.

2- N. Muñoz, J. Kim, Y. Liu, T. M. Logan, T. Ma, J. Biotechnol., 2014, 169, 95-102.

3- T. T. T. N. Nguyen, J. Ostergaard, S. Stürup, B. Gammelgaard, Int. J. Pharm., 2013, 449(1-2), 95102.

4- K. R. Murphy, G. Parcsi, R. M. Stuetz., Chemosphere, 2014, 95, 423-432.

5- K. R. Murphy, P. Wenig, G. Parcsi, T. Skov, R. M. Stuetz, 2012, Chemometr. Intell. Lab., 118, 4150.

6- P. Wenig, J. Anal. Appl. Pyrol., 2011, 92(1), 202-208.

7- http://sourceforge.net/projects/ezdata/ (Accessed 1 July 2015)

8- e-mail letter received from Anton Kavalenka (New Analytical Systems Ltd. 2015)

9- S.V. Cherepitsa, S. M. Bychkov, S. V Gatsikha, A. N. Kovalenko, A. L. Mazanik, N. M. Makoed, Meas. Tech., 2001, 44 (11), 1143-1148.

10- S. V. Cherepitsa, S. M. Bychkov, S. V. Gatsikha, 
A. N. Kovalenko, A. L. Mazanik, D. E. Kuzmenkov,

Ya. L. Luchinina, N. N. Gremyako, Chem. Tech. Fuels Oil., 2001, 37(4), 283-290.

11- P. A'Arcy, W.G. Mallard, AMDIS - User Guide, U.S. Department of Commerce, National Institute of Standards and Technology (NIST), Gaithersburg, 2008.

12- V. Behrends, G. D. Tredwell, J. G. Bundy, Anal. Biochem., 2011, 415(2), 206-208.
13- M. Cerdán-Calero, J. M. Sendra, E. Sentandreu, J. Chromatogr. A, 2012, 1241, 84-95.

14. S. Dagan, S. J. Chromatogr. A, 2000, 868(2), 229-247.

15- H. Lu, Y. Liang, W. B. Dunn, H. Shen, D. B. Kell, 2008, TrAC Trend. Anal. Chem. 27(3), 215227.

16- H.R. Norli, A. Christiansen, B. Holen, J. Chromatogr. A, 2010, 1217(13), 2056-2064.

17- K. Sichilongo, D. Banda, B. Environ. Contam. Tox., 2013, 91(5), 510-516. 